\title{
ON DEGENERATE NON-UNIFORMLY ELLIPTIC PROBLEMS
}

\author{
KAOUTHER AMMAR
}

Abstract. We are interested in the degenerate problem: $b(v)-\operatorname{div} A(v, \nabla g(v))=f$ in $\Omega$ with the boundary condition $v=a$, where $a: \partial \Omega \rightarrow \mathbb{R}$ is measurable such that $g(a)=0$. We suppose that the vector field $A$ satisfies the Leray-Lions conditions, that $b, g$ are continuous, nondecreasing with $\lim _{r \rightarrow \pm \infty}|b+g|(r)<+\infty$, that $g$ hat a flat region $\left[A_{1}, A_{2}\right]$ and is strictly increasing on $\mathbb{R} \backslash\left[A_{1}, A_{2}\right]$ for some $A_{1} \leqslant 0 \leqslant A_{2}$. Using monotonicity methods, we prove the existence and uniqueness of a renormalized entropy solution (with possibly infinite values).

Mathematics subject classification (2010): 35D05, 35J60, 35K35, 35J70.

Keywords and phrases: non-uniformly elliptic problem, non-homogenous boundary conditions, continuous flux, degenerate diffusion, infinite valued functions.

\section{REFERENCES}

[1] H. W. Alt and S. Luckhaus, Quasilinear elliptic-parabolic differential equations, Math. Z., 183 (1983), 311-341.

[2] K. AMmAR, On nonlinear diffusion problems with strong degeneracy, J. Differential Equations, 244, 8 (2008), 1841-1887.

[3] K. Ammar, On triply degenerate diffusion problems with nonhomogeneous boundary conditions, submitted in J. Differential Equations.

[4] K. Ammar, J. Carrillo And P. Wittbold, Scalar conservation laws with general boundary condition and continuous flux function, J. Differential Equations, 228 (2006), 111-139.

[5] K. AmmaR AND P. WittBold, On a degenerate scalar conservation law with general boundary condition, Diff. and Integral Equations, 21, 3-4 (2008), 363-386.

[6] K. AMmAR AND P. WitTBOLD, Existence of renormalized solutions of degenerate elliptic-parabolic problems, Proc. Roy. Soc. Edinburgh Sect. A, 133, 3 (2003), 477-496.

[7] C. BARDos, A. Y. LERouX AND J. C. NEDELEC, First order quasilinear equations with boundary conditions, Comm. in Partial Diff. Equ., 4, 9 (1979), 1017-1034.

[8] Ph. BÉnilan, J. CARRILlo And P. WitTBOld, Renormalized entropy solutions of scalar conservation laws, Ann. Scuola Norm. Sup. Pisa Cl. Sci., 29 (2000), 313-329.

[9] P. Bénilan, B. Boccardo, Gallouét, Gariephy, M. Pierre and J.L. Vazquez, An L $L^{1}$ theory of existence and uniqueness of solutions of nonlinear elliptic equations, Ann. Scuola Norm. Sup. Pisa, 22 (1995), 241-273.

[10] D. Blanchard, O. GuibÉ, Infinite valued solutions of non-uniformly elliptic problems, Analysis ans Applications, 2, 3 (2004), 227-246.

[11] D. Blanchard, O. GuibÉ AND H. Redwane, Nonlinear equations with unbounded heat conduction and integrable data, Ann. Mat. Pura Appl.(4), 187, 3 (2008), 405-433.

[12] D. Blanchard AND A. Porretta, Stefan problems with nonlinear diffusion and convection, J. Differential Equations, 210 (2005), 383-428.

[13] J. CARRILlo, Entropy solutions for nonlinear degenerate problems, Arch. Rat. Mech. Math., 147 (1999), 269-361.

[14] J. CARRillo AND P. WittBold, Uniqueness of renormalized solutions of degenerate ellipticparabolic problems, J. Differential Equations, 156 (1999), 93-121.

[15] J. CARRILLO AND P. WitTBOLD, Renormalized entropy solutions of scalar conservation laws with boundary condition, J. Differential Equations, 185 (2002), 137-160. 
[16] R. DiPerna, Measure-valued solutions to conservation laws, Arch. Rat. Mech. Anal., 88 (1985), 223-270.

[17] L. EVANS AND R. GARIEPy, Measure Theory and Fine Properties of Functions, CRC Press, 1992.

[18] S. N. KRUZHKov, Generalized solutions of the Cauchy problem in the large for first-order nonlinear equations, Soviet Math. Dokl., 10 (1969), 785-788.

[19] S. N. KRUZHKov, First-order quasilinear equations in several independent variables, Math. USSRSb., 10 (1970), 217-243.

[20] A. MiChel AND J. Vovelle, A finite volume method for parabolic degenerate problems with general Dirichlet boundary conditions, SIAM J. Num. Anal., 41, 6 (2003), 2262-2293.

[21] F. MURAT, Soluciones renormalizadas de EDP elipticas non lineales, Technical Report R93023, Laboratoire d'analyse Numérique, Paris VI, Cours à l'Université de Séville, 1993.

[22] F. Отто, Initial-boundary value problem for a scalar conservation law, C. R. Acad. Sci. Paris, 322 (1996), 729-734.

[23] A. Porretta AND J. Vovelle, $L^{1}$-solutions to first-order hyperbolic equations in bounded domains, Comm. Partial Diff. Equ., 28 (2003), 381-408. 